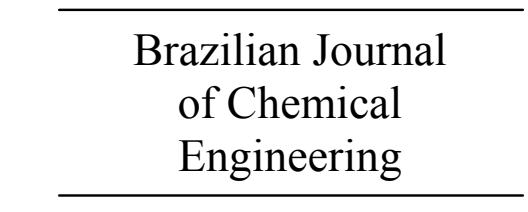

ISSN 0104-6632

Printed in Brazil

www.abeq.org.br/bjche

Vol. 31, No. 01, pp. 47 - 55, January - March, 2014

\title{
EXTENSIONAL VISCOSITY MEASUREMENTS OF CONCENTRATED EMULSIONS WITH THE USE OF THE OPPOSED NOZZLES DEVICE
}

\author{
S. Różańska ${ }^{*}$ J. Różański, M. Ochowiak and P. T. Mitkowski \\ Poznan University of Technology, Institute of Chemical Technology and Engineering, \\ Department of Chemical Engineering and Equipment, pl. M. Sklodowskiej-Curie 2, \\ 60-965 Poznan, Poland. \\ E-mail: Sylwia.Rozanska@put.poznan.pl
}

(Submitted: October 19, 2012 ; Revised: January 31, 2013 ; Accepted: March 11, 2013)

\begin{abstract}
This paper presents results of experimental studies on the apparent extensional viscosity of emulsions. The apparent extensional viscosity measurements were carried out with the use of a customized rheometer which utilizes stagnation flow between two opposing nozzles. Apparent extensional viscosity was determined for emulsions containing 60,70 and 74 vol.\% of dispersed phase. The emulsions were produced using a homogenizer equipped with different dispersing endings that resulted in emulsions characterized by different droplet sizes. The experimental results show that the value of apparent extensional viscosity of the emulsion is significantly influenced by the droplet size and by the concentration of dispersed phase. Apparent extensional viscosity as well as shear viscosity of the emulsions increases with the increase of the dispersed phase concentration and with the decrease of the droplet diameter. It has also been observed that the decrease in the diameter of droplets increases the ratio of the apparent extensional viscosity to the shear viscosity, known as the Trouton ratio.

Keywords: Concentrated emulsion; Extensional viscosity; Trouton ratio.
\end{abstract}

\section{INTRODUCTION}

Emulsions are multiphase systems, whose viscosity depends on many factors. Among the most important ones are the viscosities of the continuous and dispersed phases, the dispersed phase concentration and the droplet diameter. Two emulsions with the same chemical composition but differing in droplet diameter can be characterized by distinct rheological properties. Emulsions are widely used in various industries, such as chemical, food, cosmetic and pharmaceutical (Schramm, 1992; Malkin and Masalova, 2007; Santiago et al., 2002; Morávková and Stern, 2011). During such processes as, for example, atomization (Ochowiak et al., 2012) (fuel injection, the distribution of pesticides in agriculture, dosage of medication to the nose and throat, spray painting), dough sheeting, inlet of fluid into a pipe, spreading butter or margarine on bread, swallowing, or spreading of body lotion, fluid is subjected to stretching rather than shear (Padmanabhan, 1995). Also in various stages of processes an elongational flow (also known as extensional flow) of an emulsion can occur, for instance at the outflow of a jet during extrusion and at intersections in pipelines. The behaviour of a fluid subjected to stretching can be characterized by the extensional viscosity. Therefore, knowledge of the extensional viscosity can provide a better understanding of flow phenomena.

Research focused on the extensional viscosity was initiated by Trouton (1906). He showed that the ratio of the extensional viscosity of a Newtonian

*To whom correspondence should be addressed 
fluid under a uniaxial tensile force to the viscosity under a shear flow is equal to three. This ratio is called the Trouton ratio:

$\operatorname{Tr}=\frac{\eta_{E}}{\eta}=3$

When measuring the extensional viscosity in elongational flow, there may also be a certain amount of shear and wall effects near the surface of the jets which can contribute to the measured torque. In uniaxial extension, the extensional viscosity $\eta_{E}$ is defined as the ratio of the difference between normal stresses $\tau_{\mathrm{xx}}-\tau_{\mathrm{yy}}$ to a rate of extension $\dot{\varepsilon}$ (Chhabra and Richardson, 2008):

$\eta_{E}=\frac{\tau_{x x}-\tau_{y y}}{\dot{\varepsilon}}$

Subsequent studies, after the original Trouton (1906) work, have shown that, in the case of nonNewtonian fluids, the Trouton ratio can have values much higher than in systems satisfying Newton's law (Kennedy et al., 1995; Dontula et al., 1997; Gauri and Koelling 1997; Shiu-Kin Chan et al., 2007). For polymer and surfactant solutions, the extensional viscosity can reach values up to several hundred times greater than the shear viscosity (Jones et al., 1987; Sridhar et. al., 1991; Mansour and Chigier, 1995; Gauri and Koelling., 1997; Zirnsak and Boger, 1998; Pelletier et al., 2001; Rothstein, 2003).

Up to now there is no measurement technique which would allow determination of the equilibrium extensional viscosity of low viscosity fluids (i.e., shear viscosity below $10 \mathrm{~Pa} \cdot \mathrm{s})$. In general, there are three methods used to determine the so-called apparent extensional viscosity, namely: opposed nozzle, entry flow and capillary breakup elongational rheometer (CaBER). However, there are considerable uncertainties related to the value of the extensional viscosity that are measured with the instruments utilizing these methods. Despite this substantial disadvantage, there is a need for the way of comparing results obtained by different methods. In this work, the experiments utilized elongational flow in the opposed nozzle device, which in principle is based on the concept proposed by Fuller et al. (1987). In this method, the stagnant flow is created when fluid is sucked out simultaneously through two opposing nozzles of the same diameter.

A detailed analysis of this technique can be found in the work of Schunk et al. (1990) and Dontula et al. (1997). The values of the Trouton numbers obtained in such devices for Newtonian fluids are about 4 (Meadows et al., 1995), slightly, but consistently, higher than the predicted value of $\operatorname{Tr}=3$. This is due to the fact that only near the stagnation point is the flow nearly purely uniaxially extended. Along the walls of the nozzle shear flow is dominant. Therefore, the flow is not homogeneous, nor is it purely extensional.

The rheological properties of emulsion have been studied in many works (Bernard et al., 2005; Masalova et al., 2005; Malkin and Masalova, 2007; Derkach, 2009; Foudazi et al., 2012) and many models have been proposed for calculation of the viscosity of emulsion systems in shear flow (Einstein, 1906; Krieger and Dougherty, 1959; Pal, 1998; Kembłowski et al., 2003; Krynke and Sęk, 2004). However, in the literature only three papers about the extensional viscosity of emulsions are available (Anklam et al., 1994; Niedzwiedz et al., 2011; Różańska et al., 2013).

Anklam et al. (1994) used the opposed nozzles set-up to measure the extensional viscosities of waterin-oil emulsions. They showed that the concentration of the dispersed phase is a key factor in determination of the rheological properties of emulsions in extensional flow. Dispersed phase concentrations were varied between 30 and 80 vol.\%. The Trouton numbers obtained were approximately equal to three. In the case of emulsions with a higher concentration of the dispersed phase, the measured values of the extensional viscosity depended significantly on the nozzle diameter used in the measurement. On that basis, Anklam et al. (1994) stated that the opposing nozzles rheometer was not a suitable device for extensional viscosity measurements of concentrated emulsions. Although they also investigated oil-inwater emulsions they did not published the results.

Another study dealing with extensional viscosity was reported by Niedzwiedz et al. (2011). They presented measurement results for concentrated water-in-oil emulsions in extensional flow using a Capillary Breakup Elongational Rheometer (CaBER). Niedzwiedz et al. (2011) studied the influence of disperse volume fraction, droplet size and continuous phase viscosity on the flow properties. They showed that shear and extensional flow properties changed drastically at a critical volume fraction $\phi_{c}$, at which droplets are densely packed and start to deform. Shear flow curves revealed an apparent yield stress and strong shear thinning behaviour. They found that, for the series of investigated emulsions, the ratio of yield stress in extensional flow $\left(\tau_{y, e}\right)$ to yield stress in shear flow $\left(\tau_{y, s}\right)$ was constant $\left(\tau_{y, e} / \tau_{y, s} \approx 3\right)$.

In our earlier work (Różańska et al., 2013), we presented the rheological properties of oil in water emulsions with the addition of xanthan gum (XG), 
guar gum (GG), sodium carboxymethylcellulose (Na-CMC) or hydroxypropylmethylcellulose (HPMC) in shear and extensional flow. The results of rheological measurements showed that the extensional viscosity of the $\mathrm{o} / \mathrm{w}$ emulsions with the addition of hydrocolloids determines the properties of the continuous phase and the structure of the dispersed phase. The greatest relative increase between extensional viscosity of the emulsion and extensional viscosity of the aqueous polymer solution was observed when the dispersed phase was strongly flocculated.

The available literature data (Pal, 2000; Rámirez et al., 2002; Yakhoub et al., 2011; Foudazi et al., 2012) indicate that the rheological properties of emulsions in shear flow also depend on the concentration of dispersed phase. Some typical ranges can be distinguished here. Dilute emulsions are those in which the dispersed phase volumetric concentration $(\phi)$ is below 0.58 . When $\phi$ is between 0.58 and 0.64 , the emulsion is semidilute. As $\phi$ is further increased, the concentrated regime is reached. The droplets randomly close pack at 0.64 (Mason, 1999). The concentration of closest packing of particles, $\phi_{\mathrm{m}}$, is near 0.74 for spheres arranged in a face-centered cubic crystalline structure. These ranges are valid for monodisperse emulsions. The maximum closest packing concentration of spheres can be increased by employing different droplet sizes in such a way that smaller droplets fill the gap between bigger ones (Foudazi et al., 2012). According to Derkach et al., (2007), the dense packing of undistorted spherical droplets is around 0.72-0.74 for polydisperse emulsions.

In this paper, we report the results of measurements characterizing the $\mathrm{o} / \mathrm{w}$ emulsions with the dispersed phase volume fraction varied between 60 and 74 vol.\%. The influence of the dispersed phase concentration and droplet diameter on extensional viscosity was studied for polydisperse emulsions with the use of the opposing nozzles device.

\section{MATERIALS AND METHODS}

The rheological measurements in shear flow were carried out using the Physica MCR 501 rotational rheometer produced by Anton Parr (Germany) equipped with a cone-plate measuring system with a cone diameter of $60 \mathrm{~mm}$ and angle of $1.01^{\circ}$. All measurements were performed at a stabilized temperature of $20^{\circ} \mathrm{C}$. All the samples before measurements were kept in the thermostat for $90 \mathrm{~min}$ at $20^{\circ} \mathrm{C}$. Measurements were performed on the rheometer in an air conditioned room where the temperature was maintained at about $20 \pm 1{ }^{\circ} \mathrm{C}$. Moreover, during measurements the temperature of emulsion was continuously monitored by a temperature sensor connected to the rheometer.

During measurements the plate-plate system with a diameter of $50 \mathrm{~mm}$ was used in order to evaluate a feasibility of the effective wall slip. In the range of shear rate above $1 \mathrm{~s}^{-1}$, such an effect was not observed; therefore, all viscosity curves presented in this work were obtained with use of the cone-plate measuring configuration. The only exceptions were the values of yield stresses, for which measurements were carried out under a controlled tension. In that case, the plate-plate system with a rough surface was utilized.

Extensional viscosity was measured with the use of an opposed-nozzle device. In this study a device of our own construction was used. It is based on the concept of Fuller et al. (1987). A detailed description of the device used was presented in our previous work (Różańska et al., 2013) and is schematically presented in Figure 1. The rheometer was equipped with exchangeable opposed nozzles with diameters of 1,2 and $3 \mathrm{~mm}$. This device was also equipped with an automatic gap adjustment system between the nozzles and temperature measurement. The distance $2 h$ between the nozzles was equal to their diameter. During the measurement, the liquid was sucked out simultaneously through the two nozzles with an appropriately designed set of two computercontrolled syringes.

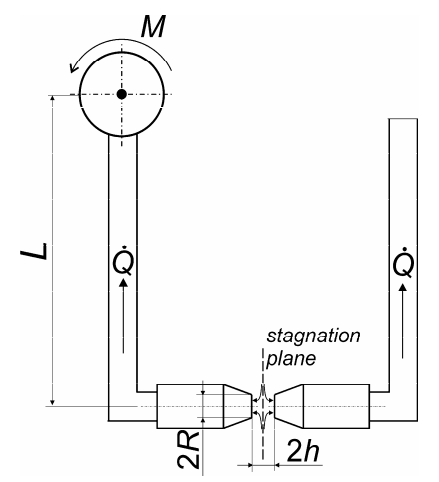

Figure 1: Scheme of the extensional rheometer utilizing stagnation flow between opposed nozzles

One of the nozzles was mounted on a movable arm connected to the torque meter (made by the private company "Roman Pomianowski Laboratory of Electronics"). Due to the relatively low values of the measured forces, it was necessary to apply a tailor-made torque meter with magnetic bearings that 
replaced the traditional mechanical bearings. The torque meter has a measurement accuracy of $\pm 1 \mu \mathrm{N}$. The setting of the nozzles was carried out manually with the use of fine two screws. In the rheometer, it was possible to achieve measurements of strain rate $(\dot{\varepsilon})$ varying between 0.9 and $1019 \mathrm{~s}^{-1}$. Apparent extensional viscosity was calculated from Equation (3) and apparent strain rate from Equation (4).

$$
\begin{aligned}
& \eta_{E}=\frac{M}{\dot{\varepsilon} \cdot \pi \cdot R^{2} \cdot L}=\frac{F \cdot h}{\dot{V}} \\
& \dot{\varepsilon}=\frac{\dot{V}}{\pi \cdot R^{2} \cdot h}
\end{aligned}
$$

For the preparation of oil in water emulsions, mineral oil with a viscosity at $20{ }^{\circ} \mathrm{C}$ of $0.582 \mathrm{~Pa} \cdot \mathrm{s}$ was used. Distilled water was used as the continuous phase. Tween 40 was used as the emulsifier and its concentration in all prepared emulsions was equal to 5 vol. $\%$.

Emulsions were made in an IKA Ultra Turrax 50 mechanical homogenizer with the use of different dispersing tips, allowing one to obtain emulsions with different droplet diameters. Table 1 summarizes the types of tips used and the value of the Sauter diameter $\left(d_{32}\right)$ defined as:

$$
d_{32}=\frac{\sum_{i} n_{i} d_{i}^{3}}{\sum_{i} n_{i} d_{i}^{2}}
$$

Microstructures of the emulsions were analysed at room temperature with use of a Nikon Eclipse 50i polarized light microscope (Tokyo, Japan). The pictures of droplets were taken by the CCD camera (OptaTech) mounted on an optical microscope. A drop of emulsion was placed between a microscope slide and cover slip. All pictures taken were analysed with Image ProPlus 6.1 image analysis software (MediaCybernetics, MD, USA), which provides precise measurement analysis of the droplet diameters. This software helps eliminate human error and maintains the highest feasible quality standard. Measurements of droplet diameters were made individually for each droplet. The average number of droplets used to calculate the Sauter's diameter was $1000 \pm 50$. The coefficient of variation provided the size distribution of the prepared emulsion droplets and was defined as:

$$
C V=\frac{\sigma}{d_{a v}} \cdot 100
$$

\section{RESULTS AND DISCUSSION}

Figure 2 shows a sample of droplet images of the emulsions with a dispersed phase concentration of $\phi=70$ vol. $\%$ obtained with three different dispersing tips. Use of three different dispersing tips resulted in emulsions with different average droplets diameters. From these images it is evident that the biggest droplets were obtained with the G45G tip. In this case, the Sauter diameter was equal to $22.1(\mu \mathrm{m})$. Application of the G45M and G45F tips yielded emulsions with droplet diameters $d_{32}$ of 11.8 and 7.1 $(\mu \mathrm{m})$ respectively. Pictures shown in Fig. 2 indicate that the emulsions studied were polydisperse and, therefore, for a more complete characterization, coefficients of variation $C V$ were calculated. The values of the $C V$ were in the range of 44.2 and 26.7 and are summarized in Table 1 . Lower $C V$ values were obtained for emulsions with smaller droplets.

The rheological properties of an emulsion can be characterized by shear viscosity $(\eta)$ and apparent extensional viscosity $\left(\eta_{E}\right)$ in terms of deformation rates, namely shear rate $(\dot{\gamma})$ and strain rate $(\dot{\varepsilon})$. Figure 3 shows a comparison of the dependencies $\eta=f(\dot{\gamma})$ and $\eta_{E}=f(\dot{\varepsilon})$ for emulsions containing 60,70 and 74 vol.\% of dispersed phase; all emulsions were prepared with use of the G45F dispersing tip. Diameters $d_{32}$ and $C V$ coefficients calculated for the emulsions with concentrations of 70 and 74 vol.\% had similar values (Table 1).

Table 1: Characteristics of selected dispersing tips.

\begin{tabular}{|c|c|c|c|c|c|}
\hline $\begin{array}{c}\phi, \\
\text { vol.\% }\end{array}$ & Types of tips & $\begin{array}{c}\text { Particle size range } \boldsymbol{\mu m} \\
\text { (by. producer) }\end{array}$ & $\begin{array}{c}\boldsymbol{d}_{\mathbf{3 2}} \\
\boldsymbol{\mu} \mathbf{m}\end{array}$ & $\begin{array}{c}\text { Standard deviation } \\
\boldsymbol{\sigma}\end{array}$ & $\begin{array}{c}\boldsymbol{C V} \\
\mathbf{\%}\end{array}$ \\
\hline \multirow{2}{*}{60} & S 50 N-G 45 G & $10-30$ & 21.7 & 6.3 & 43.5 \\
& S 50 N-G 45 F & $1-10$ & 18.2 & 5.3 & 40.7 \\
\hline \multirow{2}{*}{70} & S 50 N-G 45 G & $10-30$ & 22.1 & 6.5 & 44.2 \\
& S 50 N-G 45 M & $5-20$ & 7.1 & 2.7 & 28.7 \\
& S 50 N-G 45 F & $1-10$ & 11.8 & 4.0 & 38.4 \\
\hline \multirow{2}{*}{74} & S 50 N-G 45 G & $10-30$ & 13.1 & 3.0 & 26.7 \\
& S 50 N-G 45 F & $1-10$ & 13.9 & 5.1 & 40.7 \\
\hline
\end{tabular}




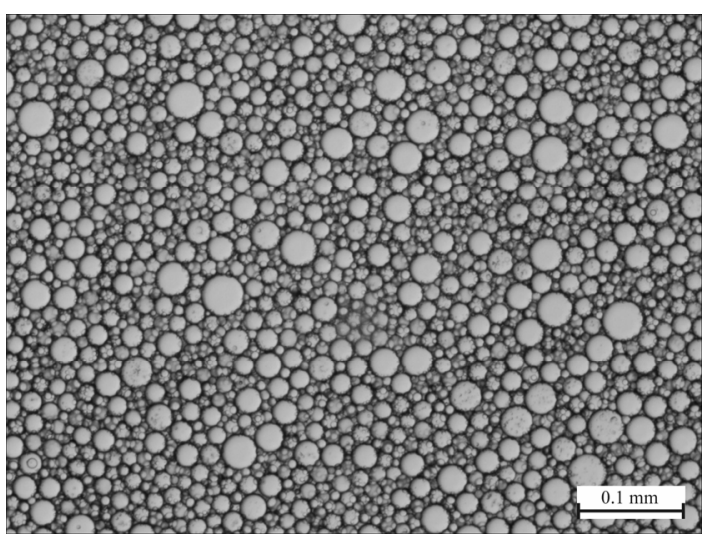

(a)

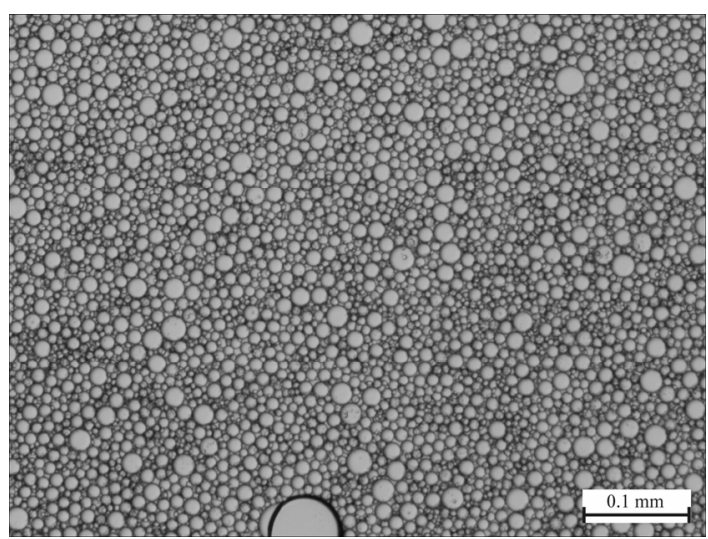

(b)

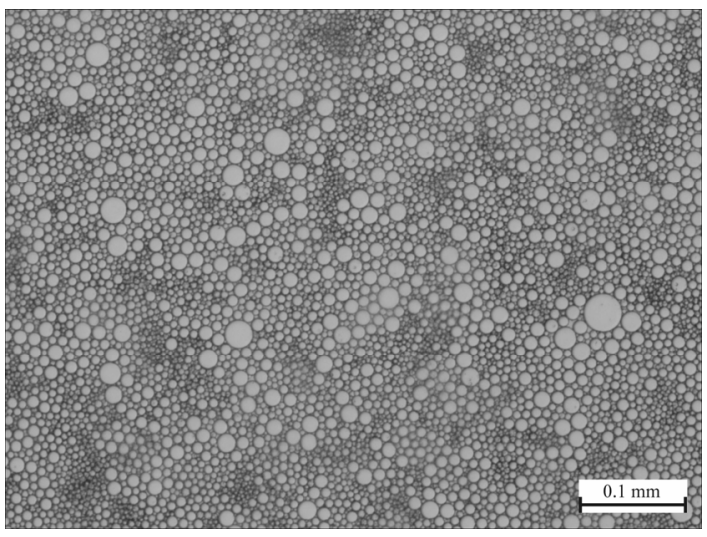

(c)

Figure 2: Images of emulsions with $\phi=70 \%$ prepared with the use of three different dispersing tips: (a) G45G, (b) G45F, (c) G45M.

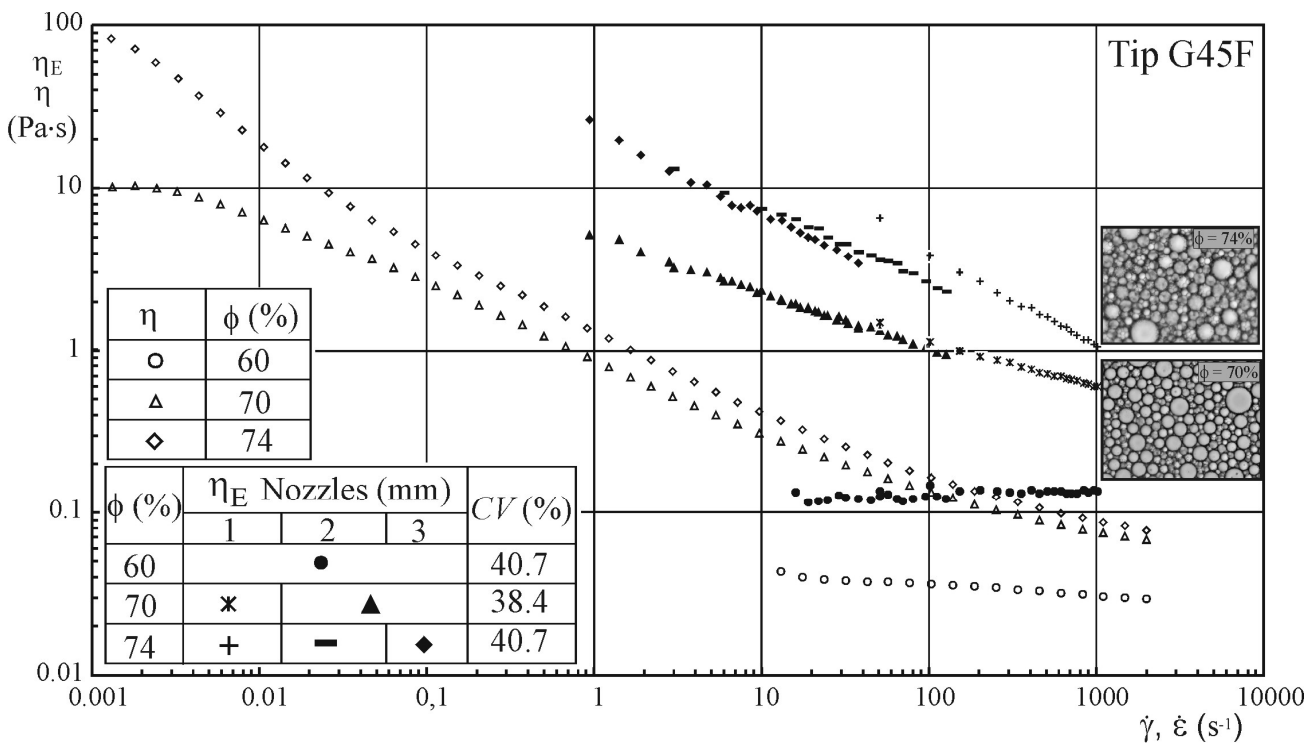

Figure 3: Extensional and shear viscosity curves of the studied emulsions prepared with the G45F tip. 
From the experimental results for shear flow of an emulsion with a concentration of $60 \mathrm{vol} \%$ it is evident that, for $\dot{\gamma}$ varying from 13 up to $2000 \mathrm{~s}^{-1}$, the shear viscosity slightly decreased from 0.043 to $0.030 \mathrm{~Pa} \cdot \mathrm{s}$. Increasing the concentration of the dispersed phase by 10 vol. $\%$ caused a significant increase in the shear viscosity, as well as in the apparent extensional viscosity. In addition, the apparent extensional viscosity of the emulsion is substantially higher than the shear viscosity. For the emulsion with a concentration of $\phi=60 \mathrm{vol} . \%$ it is independent of the strain rate and takes a constant value equal to about $0.13 \mathrm{~Pa} \cdot \mathrm{s}$.

In the case of the emulsion with a concentration of $\phi=70 \mathrm{vol} . \%$, the apparent extensional viscosity decreased with increasing strain rate. It was observed that, for nozzles with diameters of 2 and $3 \mathrm{~mm}$, the experimental points formed a single dependency, while for the nozzle with a diameter of $1 \mathrm{~mm}$ the experimental points deflected towards higher values, creating an independent relationship. However, for the emulsion with 74 vol.\% of dispersed phase three separate series of experimental points were obtained for each of the nozzles used. This indicates that this emulsion presents a nozzle size dependency, i.e., the viscosity reaches higher values with decreasing nozzle size at the same extension rate. This phenomenon was previously observed by Anklam et al., (1994). They associated the observed nozzle size dependence with the appearance of a yield stress. A fluid with a yield stress or with very high viscosity at very low shear rate $(\dot{\gamma} \rightarrow 0)$ creates a significant force on the nozzle arms, because fluid flows towards the nozzles at all points within the beaker. For the same flow rates and different sizes of nozzle Equation (2) gives various extensional rates. Therefore, the same flow rate results in a fluid tensile force dependence on the nozzle diameter. However, Anklam et al. (1994) observed that, for concentrated emulsions, the measured forces are actually independent of nozzle size at the same flow rate of fluid. On that basis, they suggested that the measured force is due to the presence of an external flow field in the beaker rather than the fluid flow between the nozzles. This effect is manifested by a decrease in apparent extensional viscosity for smaller nozzle diameters at the specified strain rate.

The data presented in Figure 3 indicate that, at a shear rate equal to $0.00131 \mathrm{~s}^{-1}$, the shear viscosity of the 74 vol.\% emulsion is higher by one order of magnitude in comparison to the 70 vol.\% emulsion. High shear viscosity at low values of $\dot{\gamma}$ probably exerts considerable force on the nozzle arm when the fluid is sucked. Therefore the nozzle diameter effect in this case can be explained by the mechanism proposed by Anklam et al. (1994).

Figure 4 shows the dependence of the ratio $(T r)$ of the extensional and shear viscosities as a function of the strain rate $\dot{\varepsilon}$. For comparative purposes the experimental points obtained for mineral oil (Newtonian fluid) of viscosity $\eta=0.5815 \mathrm{~Pa} \cdot \mathrm{s}$ with two nozzles of 1 and $2 \mathrm{~mm}$ in diameter are plotted together. The experimental values of the $\operatorname{Tr}$ number are within the limits from 3.6 to 4.2. According to the data compiled in the work of Dontula et al. (1997), it is evident that, with the use of similar devices and within similar ranges of $\dot{\varepsilon}$, the $\operatorname{Tr}$ values fall within the range from 2.9 to about 4.6. In the case of measurements of the apparent extensional viscosity utilizing the rheometer with opposed nozzles, it is not possible to fully eliminate the effects of shear and inertia on the measured values of torque, which can explain by the observed deviations from the theoretical value of $\operatorname{Tr}=3$ for the Newtonian fluids.

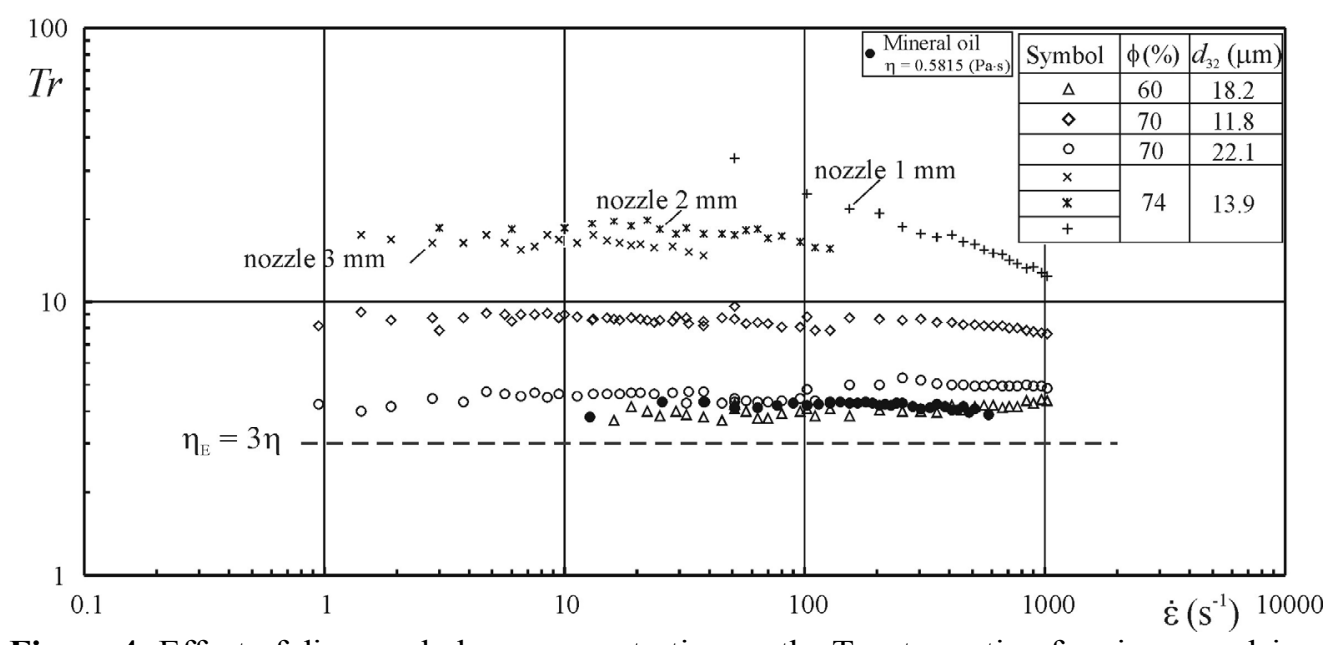

Figure 4: Effect of dispersed phase concentration on the Trouton ratio of various emulsions. 
The value of the Trouton ratio is independent of the strain rate for the Newtonian fluid, as well as for the 60 vol.\% emulsion, and it reaches values similar to pure oil. The constant value of the $\operatorname{Tr}$ number is exhibited by the emulsions of 70 vol. $\%$ concentration but with different droplet diameters $\left(d_{32}=11.8\right.$ and $22.1 \mu \mathrm{m})$. However, in that case, the $\operatorname{Tr}$ number for the emulsion with smaller droplets was larger than for Newtonian fluids and reached the average value of 8.5 for strain rates in the range from 1 to $1019 \mathrm{~s}^{-1}$. For the emulsion characterized by the larger droplet diameter $\left(d_{32}=22.1 \mu \mathrm{m}\right)$, the $\operatorname{Tr}$ ratio $(\operatorname{Tr} \approx 4.5)$ is slightly higher than the value for Newtonian fluids. In the case of the emulsion with $\phi=74$ vol. $\%$ a similar impact of nozzle diameter on the apparent extensional viscosity is observed. For nozzles with diameters of 2 and $3 \mathrm{~mm}$ the $T r$ value is almost constant; however, for the $2 \mathrm{~mm}$ nozzle it is slightly higher than that obtained with the $3 \mathrm{~mm}$ diameter nozzle. In the case of the nozzle with diameter of $1 \mathrm{~mm}$, the values of $T r$ decrease with the incre- ment of $\dot{\varepsilon}$, creating a separate series of experimental points.

Figure 5 shows curves of the shear viscosity and apparent extensional viscosity of the emulsions, for which photographs are presented in Fig. 2. Although viscosity curves indicate that the shear viscosity of emulsions having droplet diameters $d_{32}$ equal to 11.8 and $7.1(\mu \mathrm{m})$ have similar values, the apparent extensional viscosity values of these emulsions vary significantly.

In the case of the emulsion with larger droplet diameter $\left(d_{32}=22.1 \mu \mathrm{m}\right)$ and concentration of the dispersed phase $\phi=70 \mathrm{vol} . \%$, it turned out that the $T r$ ratio is approximately equal to 4.5 (Fig. 6). For the emulsion with much smaller droplets $\left(d_{32}=11.8 \mu \mathrm{m}\right)$ the average Trouton ratio increased to 8.5 , while for the emulsion with the smallest droplets $\left(d_{32}=7.1 \mu \mathrm{m}\right)$ the $\operatorname{Tr}$ ratio has the highest value of 11 . It should also be highlighted that polydisperse emulsions were used in this study, which can also have an influence on the values of extensional viscosity.

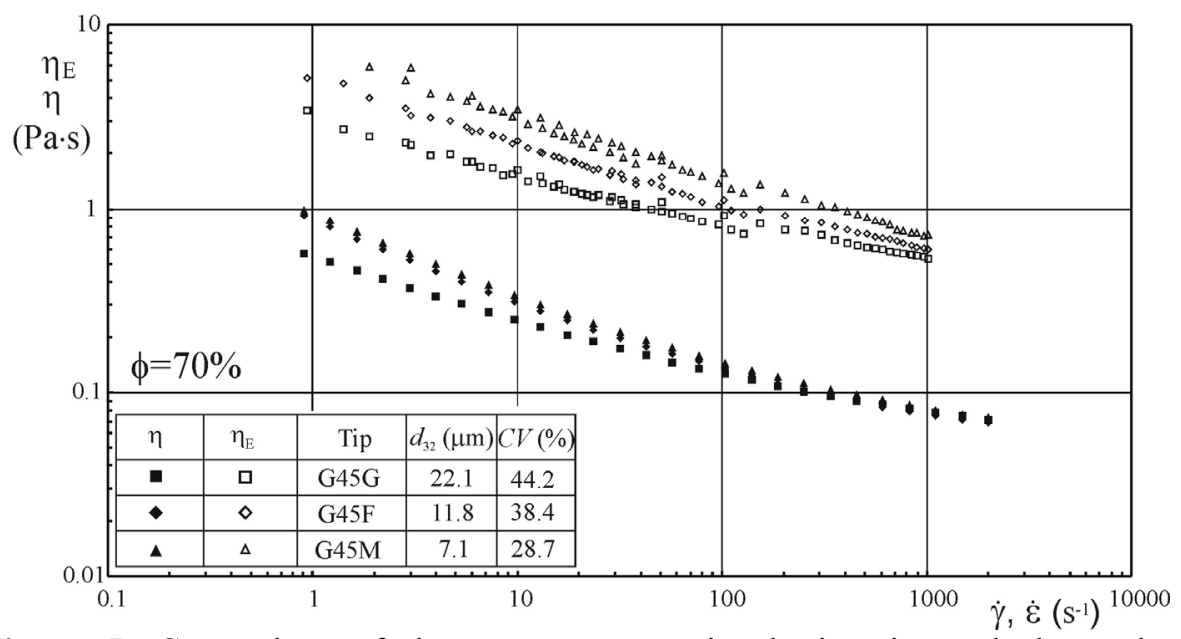

Figure 5: Comparison of the apparent extensional viscosity and shear viscosity of emulsions with $\phi=70 \%$ produced with different dispersing tips.

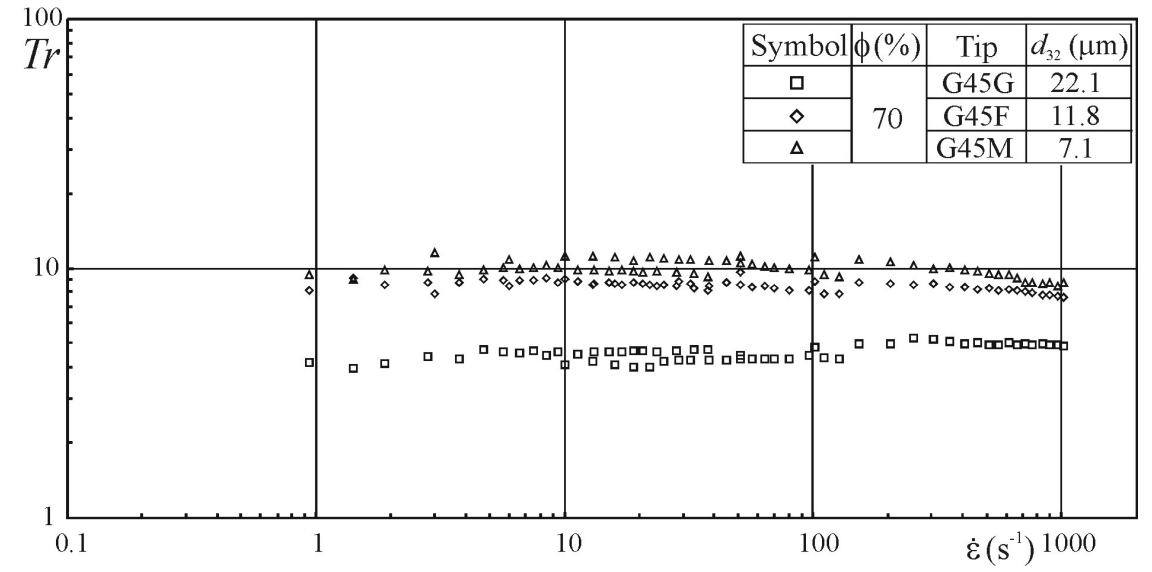

Figure 6: Trouton ratio of emulsions with $\phi=70 \%$ produced with different dispersant tips. 


\section{CONCLUSIONS}

The paper presents results of experimental studies of the apparent extensional viscosity of emulsions containing dispersed phase between 60 vol. $\%$ and 74 vol.\%. The emulsions were produced with the use of different dispersing tips due to the necessity of obtaining various average droplet diameters. Based on the results obtained it can be concluded that the apparent extensional viscosity, like the shear viscosity of the concentrated emulsion, increases with the decrease of droplet diameter. A similar effect of droplet diameters was observed on the Trouton ratio. The results show that the decrease in droplet diameter causes an increase in the apparent extensional viscosity, which is actually much more significant that in the case of shear viscosity. The courses of flow curves also show that, in the case of emulsions with dispersed phase concentrations of 70 and 74 vol.\%, the apparent extensional viscosity decreases with increasing strain rate. However, analysing the emulsion with a concentration of 74 vol.\%, the values of the apparent extensional viscosity depend on the nozzle diameter. This confirms the prior literature information, indicating that the opposing nozzle rheometer is impropriate to characterize fluids with yield stress or with high viscosity at shear rate approaching zero in extensional conditions.

\section{ACKNOWLEDGEMENTS}

This work was supported by the Ministry of Science and Higher Education, Poland, Grant No. N N209 084438 (PUT No. GR 32/844).

\section{NOMENCLATURE}

$\begin{array}{llr}C V & \text { coefficient of variation } & \% \\ M & \text { torque } & \mathrm{N} \cdot \mathrm{m} \\ L & \text { arm length } & \mathrm{m} \\ d_{a v} & \text { average diameter of emulsion } & \mu \mathrm{m} \\ & \text { droplets } & \\ h & \text { half distance between the nozzles } & \mathrm{m} \\ n_{i} & \text { number of droplets with diameter } & d_{i} \\ R & \text { radius of nozzle } & \mathrm{m} \\ \dot{V} & \text { flow rate } & \mathrm{m}^{3} / \mathrm{s} \\ T r & \text { Trouton number (ratio) } & \end{array}$

\section{Greek Letters}

$\dot{\varepsilon} \quad$ strain rate

$\phi \quad$ volume fraction of oil

$\begin{array}{lll}\eta & \text { shear viscosity } & \mathrm{Pa} \cdot \mathrm{s} \\ \eta_{E} & \text { apparent extensional viscosity } & \mathrm{Pa} \cdot \mathrm{s} \\ \sigma & \text { Standard deviation } & \end{array}$

\section{REFERENCES}

Anklam, M. R., Warr, G. G., Prud'homme, R. K., The use of opposed nozzles configuration in the measurements of the extensional rheological properties of emulsions. J. Rheology, 38, p. 797 (1994).

Bernard, P., Binks, J. H., Clint Whitby, C. P., Rheological behavior of water-in-oil emulsions stabilized by hydrophobic bentonite particles. Langmuir, 21, p. 5307 (2005).

Chhabra, R. P., Richardson, J. F., Non-Newtonian Flow and Applied Rheology. Elsevier Ltd. (2008).

Derkach, S. R., Rheology of emulsions. J. Colloid Interface Sci., 151, p. 1 (2009).

Derkach, S. R., Levachev, S. M., Kukushkina, A. N., Novoselova, N. V., Kharlov, A. E., Matveenko, V. N., Viscoelasticity of concentrated emulsions stabilized by bovine serum albumin in the presence of a nonionic surfactant. Colloid Journal, 69(2), p. 152 (2007).

Dontula, P., Pasquali, M., Scriven, L. E., Macosko, Ch. W., Can extensional viscosity be measured with opposed-nozzle devices? Rheol. Acta, 6, p. 429 (1997).

Einstein, A., Investigations on the Theory of the Brownian Movement. Dover, New York. (1906).

Foudazi, R., Masalova, I., Malkin, A. Ya., The rheology of binary mixtures of highly concentrated emulsions: Effect of droplet size ratio. J. Rheol., 56(5), p. 1299 (2012).

Fuller, G. G., Cathey, C. A., Hubbard, B., Zebrowski, B. E., Extensional viscosity measurements for low-viscosity fluids. J. Rheol., 31, p. 235 (1987).

Gauri, V., Koelling, K. W., Extensional rheology of concentrated poly(ethylene oxide) solutions. Rheol., Acta, 36, p. 555 (1997).

Jones, D. M., Walters, I., Williams, P. R., On the extensional viscosity of mobile polymer solutions. Rheol. Acta, 26, p. 20 (1987).

Kembłowski, Z., Sęk, J., Krynke, K. K., Model umożliwiający przewidywanie własności lepkich emulsji stężonych. Inż. Ap. Chem., 42(34), p. 88 (2003). (In Polish).

Kennedy, J. C., Meadows, J., Williams, P. A., Shear and extensional viscosity characteristics of a series of hydrophobically associating polyelectrolytes. J. Chem. Soc. Faraday Trans., 91(5), p. 911 (1995). 
Krieger, I. M., Dougherty, T. J., A mechanism for non-Newtonian flow in suspensions of rigid spheres. Trans. Soc. Rheol., 3, p. 137 (1959).

Krynke, K. K., Sęk, J., Predicting viscosity of emulsions in the broad range of inner phase concentrations. Colloid and Surfaces, 245, p. 81 (2004).

Malkin, A. Y., Masalova, I., Shear and normal stresses in flow of highly concentrated emulsions. J. Non-Newtonian Fluid Mech., 147, p. 65 (2007).

Mansour, A., Chigier, R., Air-blast atomization of non-Newtonian liquids. J. Non-Newtonian Fluid Mech., 58, p. 161 (1995).

Masalova, I., Taylor, M., Kharatiyan, E., Malkin, A. Ya., Rheopexy in highly concentrated emulsions. J. Rheol., 49(4), p. 839 (2005).

Mason, T. G., New fundamental concepts in emulsion rheology. Curr. Opin. Colloid Interface Sci., 4, p. 231 (1999).

Meadows, J., Williams, P. A., Kennedy, J. C., Comparison of the extensional and shear viscosity characteristics of aqueous hydroxyethylcellulose solutions. Macromolecules, 28, p. 2683 (1995).

Morávková, T., Stern, P., Rheological and textural properties of cosmetic emulsions. Appl. Rheol., 21(3), Article no. 35200 (2011).

Niedzwiedz, K., Buggisch, H., Willenbacher, N., Extensional rheology of concentrated emulsions as probed by capillary breakup elongational theometry (CaBER). Rheol. Acta., 49, p. 1103 (2011).

Ochowiak, M., Broniarz-Press, L., Różańska, S., Różański, J., The effect of extensional viscosity on the effervescent atomization of polyacrylamide solutions. J. Ind. Eng. Chem., 18, p. 2028 (2012).

Padmanabhan, M., Measurement of extensional viscosity of viscoelastic liquid foods. J. Food Eng., 25, p. 311 (1995).

Pal, R., A novel method to correlate emulsion viscosity data. Colloids Surface, A, A137, p. 275 (1998).

Pal, R., Shear viscosity behavior of emulsions of two immiscible liquids. J. Colloid Interface Sci., 225, p. 359 (2000).

Pelletier, E., Viebke, C., Meadows, J., Williams, P. A., A rheological study of the order-disorder conformational transition of xanthan gum. Biopolymers, 59, p. 339 (2001).

Rámirez, M., Bullón, J., Andérez, J., Mira, I., Salager, J-L., Drop size distribution bimodality and its effect on $\mathrm{O} / \mathrm{W}$ emulsion viscosity. J. Dispersion Science and Technology, 23(1-3), p. 309 (2002).

Rothstein, J. P., Transient extensional rheology of wormlike micelle solutions. J. Rheol., 47(5), p. 1227 (2003).

Różańska, S., Broniarz-Press, L., Różański, J., Mitkowski, P. T., Ochowiak, M., Woziwodzki, S., Extensional viscosity of $\mathrm{o} / \mathrm{w}$ emulsion stabilized by polysaccharides measured on the opposed-nozzle device. Food Hydrocoll., 32, p. 130, (2013).

Santiago, L. G., Gonzalez, R. J., Fillery-Travis, A., Robins, M., Bonaldo, A. G., Carrara, C., The influence of xanthan and $\lambda$-carrageenan on the creaming and flocculation of an oil-in-water emulsion containing soy protein. Braz. J. Chem. Eng., 19(4), p. 411 (2002).

Schramm, L. L., Emulsions: Fundamentals and Applications in the Petroleum Industry. American Chemical Society, Washington, DC (1992).

Schunk, P. R., de Santos, J. M., Scriven, L. E., Flow of Newtonian liquids in opposed-nozzles configuration. J. Rheol., 34, p. 387 (1990).

Shiu-Kin Chan, P., Chena, J., Ettelaiea, R., Lawa, Z., Alevisopoulosb, S., Dayb, E., Smith, S., Study of the shear and extensional rheology of casein, waxy maize starch and their mixtures. Food Hydrocoll., 21, p. 716 (2007).

Sridhar, T., Tirtaatmadja, V., Nguyen, D. A., Gupta, R. K., Measurement of extensional viscosity of polymer solutions. J. Non-Newtonian Fluid Mech., 40, p. 271 (1991).

Trouton, F. T., On the coefficient of viscous traction and its relation to that of viscosity. Proc. Roy. Soc., A77, p. 426 (1906).

Yakhoub, H. A., Masalova, I., Haldenwang, R., Highly concentrated emulsions: Role of droplet size. Chem. Eng. Comm., 198, p. 147 (2011).

Zirnsak, M. A., Boger, D. V., Axisymmetric entry flow of semi-dilute xanthan gum solutions: Prediction and experiment. J. Non-Newtonian Fluid Mech., 79, p. 105 (1998). 